\title{
Biological invasions as disruptors of plant reproductive mutualisms
}

\author{
Anna Traveset ${ }^{1}$ and David M. Richardson ${ }^{2}$
}

\begin{abstract}
${ }^{1}$ Mediterranean Institute of Advanced Studies (CSIC-UIB), C/ Miquel Marqués 21, E07190 Esporles, Mallorca, Balearic Islands, Spain ${ }^{2}$ Centre for Invasion Biology, Department of Botany \& Zoology, University of Stellenbosch, Private Bag X1, Matieland 7602,

South Africa
\end{abstract}

Invasive alien species affect the composition and functioning of invaded ecosystems in many ways, altering ecological interactions that have arisen over evolutionary timescales. Specifically, disruptions to pollination and seed-dispersal mutualistic interactions are often documented, although the profound implications of such impacts are not widely recognized. Such disruptions can occur via the introduction of alien pollinators, seed dispersers, herbivores, predators or plants, and we define here the many potential outcomes of each situation. The frequency and circumstances under which each category of mechanisms operates are also poorly known. Most evidence is from populationlevel studies, and the implications for global biodiversity are difficult to predict. Further insights are needed on the degree of resilience in interaction networks, but the preliminary picture suggests that invasive species frequently cause profound disruptions to plant reproductive mutualisms.

\section{Introduction}

Biological invasions threaten global biodiversity by altering the structure and functioning of ecosystems $[1,2]$. Invasive plant species (see Glossary) often modify system-level flows and the availability and/or quality of space and resources [2,3]. Many studies have focused on the impacts of invaders on species diversity and community composition and functioning, but only a few have explored the underlying mechanisms [2]. Although invasive species can cause the extinction of native ones, goodquality supporting data are scarce [4]. It is known, however, that invaders can alter ecological interactions that have arisen over evolutionary timescales and, thus, could modify evolutionary trajectories. In particular, alien species can disrupt mutualistic plant-animal interactions, such as pollination or seed dispersal [5-8]. Here, we review the information available on this subject and identify the range of mechanisms by which invaders can interfere with mutualistic interactions. In so doing, we evaluate the vulnerability of such interactions at a global scale. However, insufficient information is available to enable us to compare the impacts of invasive species on mutualisms with those of direct competition for space, light, soil nutrients or water.

Corresponding author: Traveset, A. (atraveset@uib.es).

Available online 7 February 2006
Pollination and seed-dispersal mutualisms can have a fundamental role in the regeneration of natural communities and are crucial for maintaining the structure and diversity of some ecosystems $[5,9,10]$. We thus must be able to predict the ecological and evolutionary impact of any factor that can disrupt them. Most information available about mutualistic disruptions owing to biological invasions is from islands, although an increasing number of studies provide data from continental areas. Biological invasions appear to pose a greater hazard on islands than on continents mainly because of the intrinsic characteristics of the island biota, such as smaller population sizes and isolated evolution $[8,11,12]$.

\section{Disruption of plant-pollinator interactions}

Most angiosperm species rely either facultatively or obligatorily on animals for seed production. Many of those plants are generalists, being visited by a wide

\footnotetext{
Glossary

Allelopathy: the production of specific biomolecules by one plant, mostly secondary metabolites, that can influence the growth and development of other neighbouring plants.

Invasive species: here, 'invasive' always refers to alien species (those whose occurrence in an area is due to their introduction, intentionally or accidentally, as a result of human activity) that recruit reproductive offspring, often in large numbers, at considerable distances from parent plants and, thus, can spread at a considerable rate.

Disruption of pollinator-plant or seed disperser-plant interactions: the effect that any factor (habitat fragmentation, introduction of alien species, hunting, etc.) could have on the quantitative and/or qualitative components of pollination or dispersal effectiveness and, ultimately, on plant fitness. Quantitative aspects refer to the number of pollen grains deposited or the number of seeds dispersed. Qualitative changes involve the value of either the pollen (in genetic terms) or the microhabitat where seeds are left [10].[10] Endozoochory: seed dispersal carried out by frugivorous animals that ingest fleshy fruits and defecate or regurgitate viable seeds intact.

Invasional meltdown: process by which a group of alien species facilitate one another's invasion in various ways, increasing the likelihood of survival and/or of ecological impact, and possibly the magnitude of impact [50].[50]

Legitimate pollination or dispersal: pollination or dispersal that is effective. A legitimate pollinator contacts the reproductive organs of the flowers and transports pollen among flowers. A legitimate disperser consumes the fruits and transports their seeds to adequate sites for germination and seedling growth.

Mutualistic compartments: functional groups of species linked by exclusive or frequent mutualisms (e.g. deep-corolla plants pollinated by long-tongued bees).

Native taxa: those that have originated in a given area without human involvement or that arrived there without intentional or unintentional intervention of humans from an area in which they are native (synonyms: indigenous taxa).

Seed set: number of seeds produced relative to the number of flowers.
} 
diversity of pollinators that, in turn, visit flowers of a great variety of species [13]. Therefore, introduced pollinators $[14,15]$ or plants [16] have a good chance of integrating within pollination webs in the newly invaded ecosystems. Here, we explore the mechanisms whereby invaders in four broad categories could modify the outcome of native plant-pollinator mutualisms, and we give examples of systems already disrupted (Table 1).

\section{Introduction of an alien pollinator}

An alien pollinator is likely to have negative effects on plant populations if it decreases the quantity and/or quality of pollen transferred among plants, resulting in reduced seed set and decreased plant fitness (Figure 1). Plants that are usually seed limited are likely to be the most vulnerable [17,18]. Moreover, a quantitatively important pollinator (with high flower visitation rates) might be a poor-quality pollinator if it does not transfer pollen effectively [19-21]. The same properties that make a pollinator invasive (e.g. high rates of intrinsic population increase) might also be associated with the proportion of pollen that is fed to young instead of being transferred among plants. Nevertheless, alien pollinators might either increase plant fitness by increasing pollen transfer among plants $[6,22,23]$, or have no effect if flower visitation rate is relatively low [24] or if such increased pollen transfer does not increase reproductive success.

That most invasive pollinators are generalists facilitates their integration into native mutualistic webs and, in turn, their establishment and spread within the invaded ecosystems $[15,22,24]$. Such a generalized foraging syndrome makes the interactions with native plants diffuse and relatively weak and, thus, the impact on native mutualisms might be weaker than expected. Native plants visited by several native pollinators are likely to be more buffered from any negative (or positive) impacts of an alien pollinator than are plants that depend upon only one or two pollinators. However, a highly coevolved specialist mutualism might be more protected against any alien entering the pollination web. The scarce data currently available preclude testing such hypotheses. Traits other than the degree of generalism and pollinator-limited seed set that could make plants more susceptible to the influence of alien pollinators include a low native pollinator constancy, a restricted flowering period, few floral rewards, or low flower and seed crops [17].

Honeybees Apis mellifera are a typical example of a successful worldwide pollinator invasion. They visit many plant species and are quantitatively effective pollinators in several mutualistic systems $[22,23,25,26]$, although are qualitatively poorer pollinators than are natives in others $[6,12,19,20,27]$. Honeybees often decrease flower visitation rate by native pollinators through exploitative or interference competition $[12,23,28]$ and can alter plant genetic structure by promoting greater levels of selfing $[12,28,29]$. Such competition has a potentially negative impact on plant fitness $[12,19,20,28]$, although no cascading consequences have yet been demonstrated $[22,26]$.

Native pollinators might be outcompeted by an invasive pollinator depending upon the competitive superiority of the invader and whether resources were limiting. Different studies have claimed competition between introduced honeybees and native pollinators, although only a few have measured competition directly $[5,22,25]$. Other invasive insects, such as bumblebees Bombus terrestris, the alfalfa leafcutter bee Megachile rotundata and wasps in the genus Vespula, are also potentially harmful to native pollinators $[14,24,26]$. Long-term studies on fecundity, survival or population density of native pollinators are lacking but are essential for assessing the threat that such invasive insects pose to native pollinators $[25,26,30]$. Likewise, the long-term consequences of changes in the local pollinator fauna for the native flora also require investigation.

Invasive pollinators can also replace lost or declining native pollinators to some extent. This has been found in fragmented landscapes [23,29] and in several oceanic islands: for example, in Hawaii, the vine Freycinetia arborea (originally pollinated by now-extinct bird species) survives thanks to the Japanese silvereye Zosterops japonica [11]; in Mauritius, the introduced red-whiskered bulbul Pycnonotus jocosus visits the flowers of the extremely rare endemic Nesocodon mauritianus more frequently than do native birds [31]; and in New Zealand, the recently arrived silvereye Zosterops lateralis has replaced several species of extinct or declining native bird pollinators [24]. The ecological and evolutionary consequences of such replacements for the plants are still unknown.

\section{Introduction of an alien herbivore}

An animal that consumes vegetative or reproductive parts of a plant can exert considerable influence on plantpollinator mutualisms. Such influence can be directly negative for the plant (e.g. by consuming flowers) and/or for the pollinator (by reducing resources such as nectar and pollen). For example, in New Zealand, the eradication of introduced possums Trichosurus vulpecula and wallabies Petrogale penicillata from some islands has led to significant increases in the flowering of several plant species that, in turn, have increased the population sizes of their bird pollinators [32]. Introduced herbivores, particularly ungulates, are usually generalists and can significantly affect plant-pollinator mutualisms in invaded areas [33]. The simple impact of trampling can result in smaller population sizes and, thus, indirectly affect patterns of pollination visits and plant reproductive success [33]. From an evolutionary perspective, herbivores could also counteract pollinator-mediated selection on floral traits, such as flowering phenology, quantity and quality of floral nectar, pollen performance or flower number [34].

\section{Introduction of an alien predator}

An introduced invasive predator can alter the population growth of pollinators and, in turn, indirectly affect the fitness of plants that strongly depend upon them. In the Canary and Balearic Islands, alien carnivores have led to the extinction of native lizards that were important pollinators for a variety of plant species $[35,36]$. Introduced rats, cats and stoats in New Zealand have reduced 
Table 1. Invasive species that have altered native plant-pollinator mutualisms and the presumable magnitude of the effect based on available data

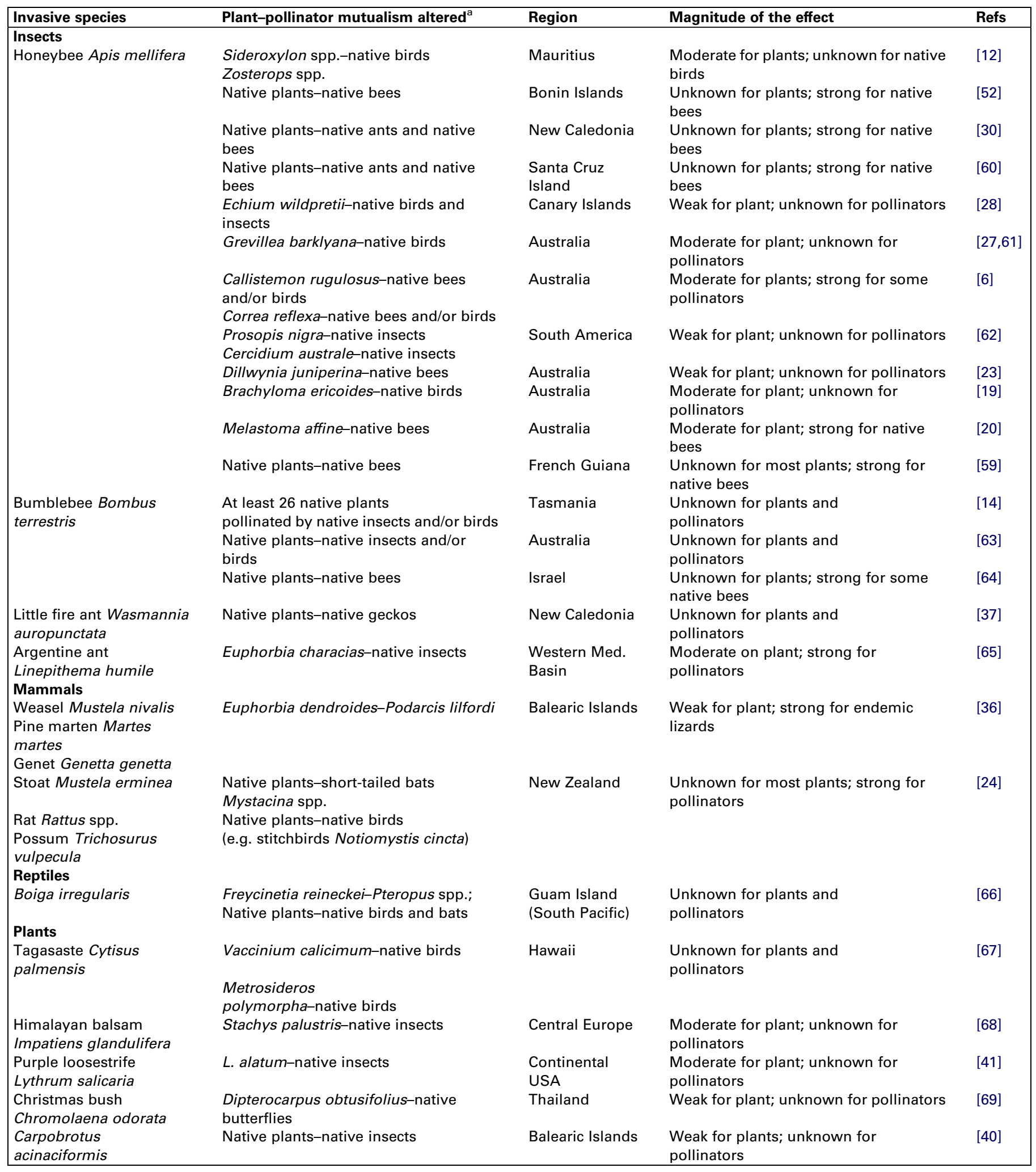

${ }^{a}$ When no specific names are given, several or many species are involved.

populations of endemic nectarivorous birds and bats that pollinate a diverse array of plants, some of which are now pollen limited [24]. In New Caledonia, the invasive ant Wasmannia auropunctata is threatening populations of several species of geckos [37] that pollinate and disperse several plant species (T. Whitaker, personal communication). Given the global importance of such ant invasions [38], it is necessary to determine how they influence the 


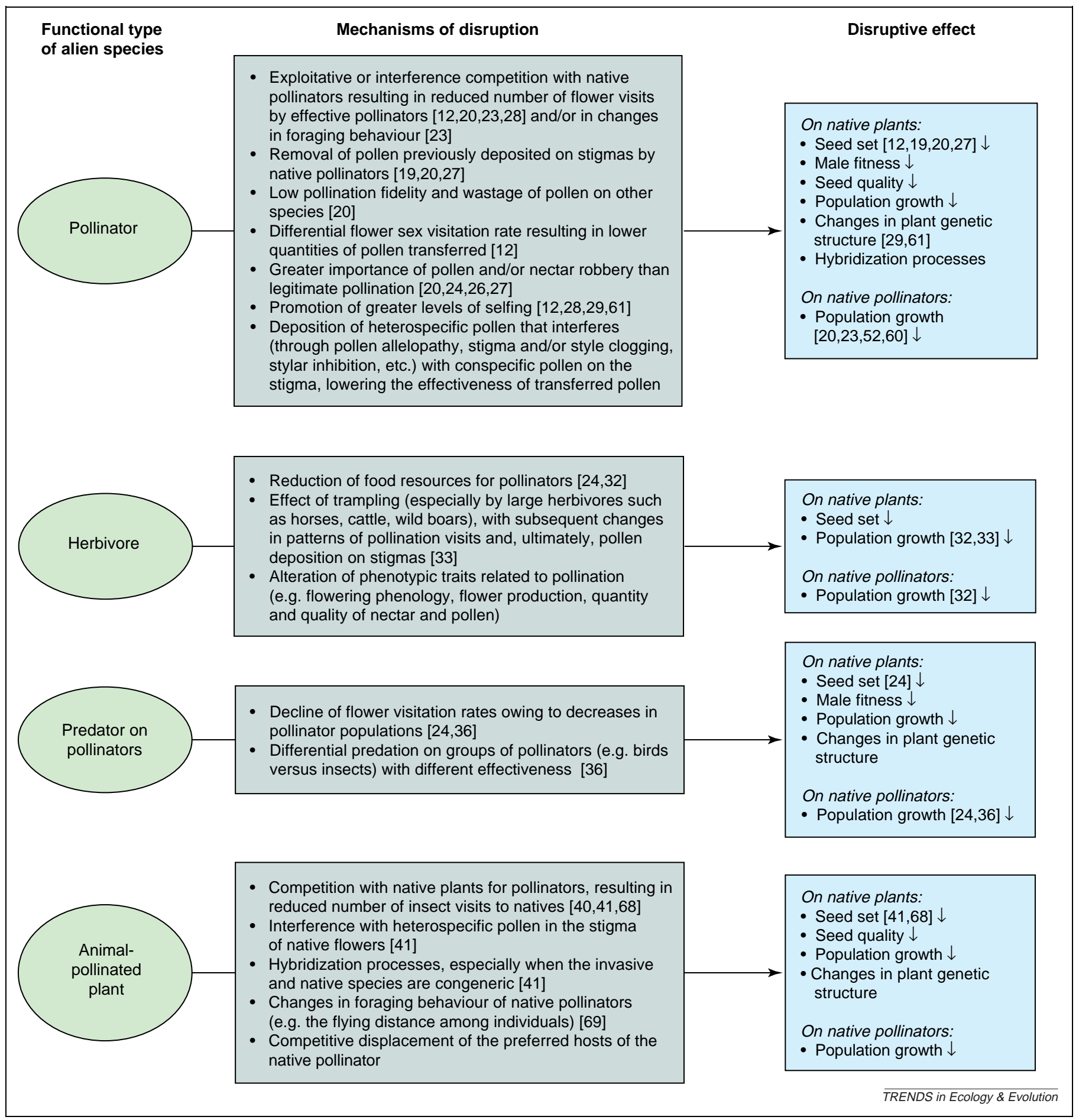

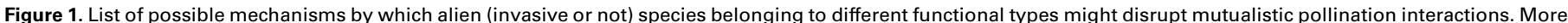

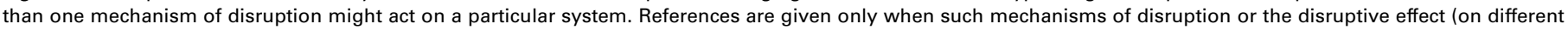

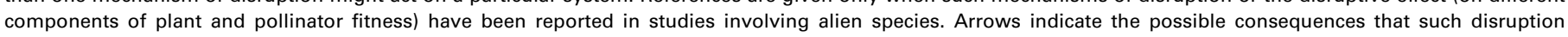
mechanisms can lead to.

outcome of plant-animal mutualisms. Predator species, such as carnivorous species on islands, that can displace native fauna from their habitats are perhaps the most likely to disrupt native plant-pollinator interactions, especially in specialized systems [8].

Moreover, the indirect effects on native mutualists through the introduction of diseases or parasites carried by alien species require further investigation. Malaria transmitted by introduced mosquitoes in Hawaii, for instance, has contributed to the extinction of over a third of the endemic bird species, with probable cascading effects on many endemic ornithophilous plants [11].

\section{Introduction of an alien plant}

An animal-pollinated invasive plant has great potential to disrupt interactions between native plants and pollinators in various ways (Figure 1). As most invasive plants are pollinator generalists, their integration into 
pollination webs is facilitated and, in turn, their establishment and spread can be enhanced, by such mutualists [39]. An invasive plant bearing rich floral resources, with large or prolonged floral displays (e.g. Carpobrotus spp., Lantana camara, Mimosa pigra), could have a strong impact on a native plant if it was preferred by pollinators and this resulted in a lower reproductive success of the native. Only a few studies have investigated the competition for pollinators between alien and native plants (Table 1) and most have found evidence for it, although a facilitative effect is also possible [40]. Competition has been reported with the invasive Asian Impatiens glandulifera, which reduces the number of pollinators and seed set of the native Stachys palustris by $\sim 50 \%$ and $\sim 25 \%$, respectively; the invader Chromolaena odorata in a tropical dry forest in Thailand also reduces the frequency of butterfly visits to flowers of the native Dipterocarpus obtusifolius (Table 1). Sharing pollinators can also imply hybridisation processes, especially between congeneric species, with implications for the native plant fitness, as reported for the genus Lythrum in the continental USA [41]. Other potential pollinator-mediated effects of invasive plants on native flora include changes in gene flow and decreased quality of pollen delivered, with subsequent reduction in seed set [41].
Invasive plants can also have direct effects on the native pollinator fauna. Plants benefit from the mutualism established with native fauna [39], but pollinators, in turn, benefit from the new resources. In northern New South Wales, plant invasions appear important for maintaining animal populations in fragmented systems (C.R. Gosper, PhD thesis, University of Wollongong, 2004) and the butterfly fauna of an urban Californian area depends mainly on naturalized weeds [42]. However, alien plants can also reduce the reproductive success of pollinators if, for instance, the plants are toxic to larvae of the insects that visit and oviposit on them [42]. An invasive plant might also indirectly impact the pollinator fauna of the invaded area if it competitively displaces the preferred hosts of the native pollinators.

\section{Disruption of plant-seed disperser interactions}

Animal dispersers contribute significantly to maintaining the structure and diversity of different natural communities (e.g. flying foxes in the South Pacific islands [11] or ants in South African fynbos [7]) and can have an important role in many others, for example in humid tropical forests, where vertebrates disperse $75-90 \%$ of the woody taxa [10]. Despite the loss of native dispersers as a result of widespread invasions [7,11,24], impacts on seed dispersal mutualisms are still poorly documented (Table 2).

Table 2. Invasive species that have altered native plant-dispersal mutualisms and the presumable magnitude of the effect based on available data

\begin{tabular}{|c|c|c|c|c|}
\hline Invasive species & $\begin{array}{l}\text { Plant-dispersal mutualism } \\
\text { altered }^{\mathrm{a}}\end{array}$ & Region & Magnitude of effect & Refs \\
\hline \multicolumn{5}{|l|}{ Insects } \\
\hline $\begin{array}{l}\text { Argentine ant Linepithema } \\
\text { humile }\end{array}$ & Native plants-native ants & $\begin{array}{l}\text { South African fynbos; Wes- } \\
\text { tern Med. Basin; California }\end{array}$ & $\begin{array}{l}\text { Strong for some plants; } \\
\text { strong for dispersers }\end{array}$ & {$[7,70,71]$} \\
\hline $\begin{array}{l}\text { Little fire ant Wasmannia } \\
\text { auropunctata }\end{array}$ & Native plants-native geckos & New Caledonia & $\begin{array}{l}\text { Unknown for plants and } \\
\text { dispersers }\end{array}$ & [37] \\
\hline \multicolumn{5}{|l|}{ Birds } \\
\hline $\begin{array}{l}\text { Starling Sturnus vulgaris } \\
\text { Blackbird Turdus merula } \\
\text { Song thrush Turdus } \\
\text { philomelos }\end{array}$ & Native plants-native birds & New Zealand & $\begin{array}{l}\text { Unknown for plants and } \\
\text { dispersers }\end{array}$ & [43] \\
\hline $\begin{array}{l}\text { White-eye Zosterops } \\
\text { japonicus }\end{array}$ & $\begin{array}{l}\text { Native plants-endemic } \\
\text { White-eye Apalopteron } \\
\text { familiare }\end{array}$ & Bonin Islands & Weak for plants and birds & {$[72]$} \\
\hline \multicolumn{5}{|l|}{ Mammals } \\
\hline Stoat Mustela erminea & $\begin{array}{l}\text { Native plants-short-tailed } \\
\text { bats Mystacina spp. }\end{array}$ & New Zealand & $\begin{array}{l}\text { Unknown for most plants; } \\
\text { strong for endemic dispersers } \\
\text { (in severe decline) }\end{array}$ & {$[24,32]$} \\
\hline Rat Rattus spp. & Native plants-native birds & & & \\
\hline $\begin{array}{l}\text { Possum Trichosurus } \\
\text { vulpecula } \\
\text { Cat Felis catus }\end{array}$ & $\begin{array}{l}\text { (e.g. kokako Callaeas cinerea, } \\
\text { kereru Hemiphaga novaesee- } \\
\text { landiae) }\end{array}$ & & & \\
\hline $\begin{array}{l}\text { Pine marten Martes martes } \\
\text { Genet Genetta genetta } \\
\text { Weasel Mustela nivalis } \\
\text { Cat } F \text {. catus }\end{array}$ & $\begin{array}{l}\text { Native plants-native birds/ } \\
\text { lizards (Podarcis spp.) }\end{array}$ & Balearic Islands & $\begin{array}{l}\text { Strong for some plants; } \\
\text { strong for dispersers (extinct } \\
\text { from some islands) }\end{array}$ & {$[8,45]$} \\
\hline Cat F. catus & $\begin{array}{l}\text { Native plants-Gallotia spp. } \\
\text { (endemic lizards) }\end{array}$ & Canary Islands & $\begin{array}{l}\text { Unknown for most plants; } \\
\text { strong for dispersers }\end{array}$ & [35] \\
\hline \multicolumn{5}{|l|}{ Plants } \\
\hline $\begin{array}{l}\text { Wild tobacco bush Solanum } \\
\text { mauritianum }\end{array}$ & $\begin{array}{l}\text { Native plants-Rameron } \\
\text { pigeon Columba arquatrix }\end{array}$ & South Africa & $\begin{array}{l}\text { Strong for most plants; } \\
\text { unknown for dispersers }\end{array}$ & [48] \\
\hline $\begin{array}{l}\text { Hawthorn Crataegus } \\
\text { monogyna }\end{array}$ & $\begin{array}{l}\text { Crataegus douglassi } \\
\text { suksdorfii-native birds }\end{array}$ & Continental USA & $\begin{array}{l}\text { Unknown for plant and } \\
\text { dispersers }\end{array}$ & [47] \\
\hline $\begin{array}{l}\text { Chrysanthemoides } \\
\text { monilifera }\end{array}$ & Native plants-native birds & New South Wales, Australia & $\begin{array}{l}\text { Strong for most plants; } \\
\text { unknown for dispersers }\end{array}$ & b \\
\hline
\end{tabular}

${ }^{a}$ When no specific names are given, several or many species are involved.

${ }^{b}$ C.R. Gosper, PhD thesis, University of Wollongong, 2004.

www.sciencedirect.com 


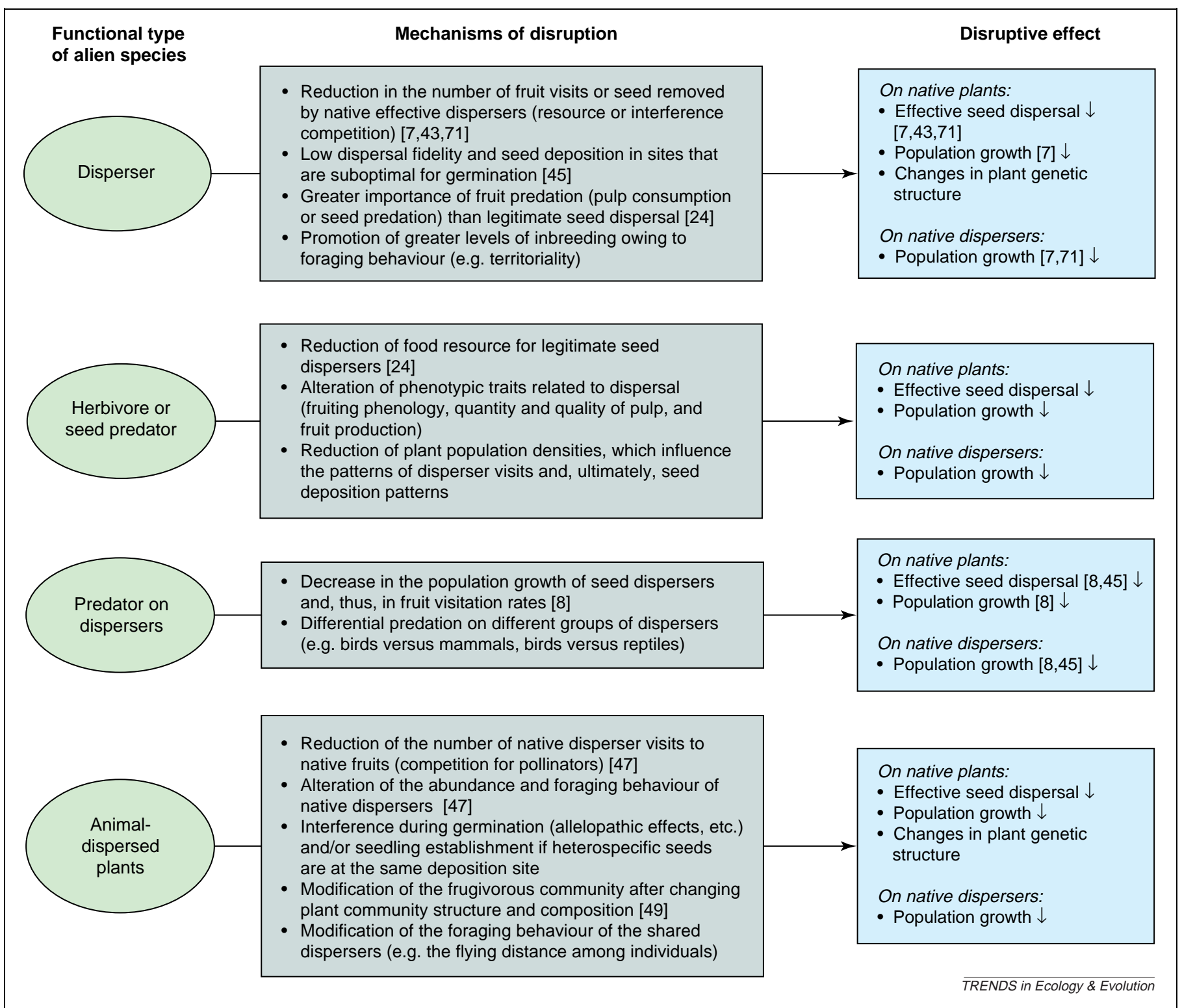

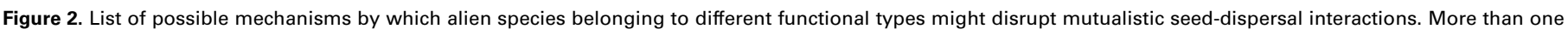

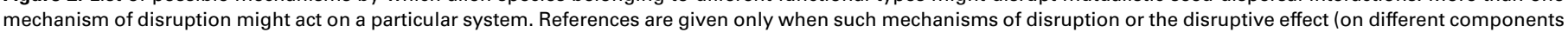
of plant and disperser fitness) has been reported for alien species. Arrows indicate the possible consequences that such disruption mechanisms can lead to.

As in the case of pollination, there is a high level of generalism in seed-dispersal systems; endozoochorous plants usually rely on a wide range of species that, in turn, consume the fruits of a variety of plants [13]. Therefore, alien dispersers or plants encounter few obstacles to infiltrating native seed dispersal networks. We explore here the possible mechanisms whereby invaders can disrupt the native plant-disperser interactions (Figure 2).

\section{Introduction of an alien seed disperser}

An introduced frugivorous animal can be an effective seed disperser of many native plants [24,43-45] and might even increase plant fitness when seed dispersal is limiting [44]. By contrast, its effect on plant populations might be either low [24], or even detrimental, if it is an inefficient disperser that, for example, deposits most seeds on sites that are unsuitable for germination [45], if it outcompetes legitimate native dispersers [43], and/or it modifies either the seed shadow or the germination patterns generated by native dispersers [45]. As in pollination systems, the quantity and quality components of dispersal effectiveness might not be correlated and, thus, both need to be assessed to determine the relative importance of an alien disperser for plant dispersal [24]. The impact of such a disperser is likely to be low if fruits are abundant and not limiting, if its fruit visitation rates are relatively low, if it has similar foraging behaviour to natives, and/or if the plant does not strongly rely on dispersers for regeneration.

Native dispersers might be negatively affected by an alien seed disperser that is competitively superior to them, especially if resources are scarce. Alien grey squirrels Sciurus carolinensis, for instance, displace native squirrels $S$. vulgaris in Europe [46], with probable negative (but as yet unconfirmed) consequences for the plants dispersed by the latter. If there is no competition between alien and native dispersers, the impact will be minimal [47]. 
Introduction of a herbivore (including seed predators) The dispersal success of a plant can be modified by introduced herbivores (e.g. parrots, rats and goats) either directly by consuming vegetative or reproductive parts and decreasing seed dispersal rates [24], or indirectly by negatively affecting populations of native legitimate dispersers, as found in the South African fynbos, where the Argentine ant Linepithema humile has displaced native ants, subsequently reducing plant densities of large-seeded Proteaceae that depended upon them and, ultimately, altering plant community composition [7]. The impact of the ant $W$. auropunctata in many parts of the world $[37,38]$ might be shown to be as strong.

\section{Introduction of an alien predator}

Alien animals that prey on native dispersers can influence plant dispersal success. To date, all evidence is from island systems. In New Zealand, introduced posssums, ship rats, cats and stoats are altering the populations of native seed dispersers, such as stitchbirds and short-tailed bats Mystacina robusta and M. tuberculata [24,32]. Carnivorous mammals introduced in the Balearics led to the extinction of the lacertid Podarcis lilfordi from some of these islands, causing, in turn, the regression of Daphne rodriguezii, an endemic shrub that depends upon the lizard for dispersal [8].

\section{Introduction of an alien plant}

A fleshy fruited invasive plant that reaches a new area could alter in many ways the dispersal patterns of native plants that fruit simultaneously but that have either less attractive or more concentrated fruit displays. Such competition for dispersers has been documented in Australia (C.R. Gosper, PhD thesis, University of Wollongong, 2004), Oregon [47] and South Africa [48]. Moreover, a mixed diet of alien and native fruits might result in native seeds being dispersed in microhabitats that are unsuitable for germination. Germination of native seeds might be altered further as a result of allelopathic effects caused by alien species. In addition, an invasive plant might alter the composition, morphology and structure of the native plant community, resulting in the modification of the animal community that feeds upon fruits or seeds. For instance, the invasive gorse Ulex europaeus has replaced New Zealand communities dominated by the native kanuka Kunzea ericoides, changing the proportion of seed-dispersing mammals and birds [49].

\section{Invasional meltdowns}

Positive interactions among alien species are increasingly common, particularly plant-pollinator and dispersal interactions [39,50]. For instance, introduced honeybees are important pollinators of several alien species, both on continents [50,51] and islands such as Bonin [52], New Zealand [26], Tasmania [53] Azores [15] and Santa Cruz [54]. Several Bombus species and Megachile rotundata often prefer alien flowers in New Zealand and Australia, respectively [26]. Alien fig wasps also trigger the expansion of invasive fig species in continental USA, Hawaii and New Zealand [50]. Rats and rabbits disperse the seeds of the invasive ice plant Carpobrotus spp., contributing to its expansion along the Californian coast [54] and on Mediterranean islands [55]. European starlings Sturnus vulgaris in New Zealand are important dispersers of alien plants such as Solanum spp., Phytolacca americana and Rubus fruticosus [43]. The red-whiskered bulbul P. jocosus disperses many alien species in La Réunion Island and in Florida, whereas $Z$. japonica in Hawaii is a primary disperser of the invasive Myrica faya [50].

Such invasional meltdowns disrupt native plantanimal mutualisms because they modify the structure of native plant communities and the foraging behaviour and movement patterns of the animal mutualists. On islands, because of the relatively lower species richness and the presence of endemic generalists [15], we would expect a stronger effect of such invader complexes. Further studies that explore the impact of such invasive species on the structures of either pollination or dispersal webs are needed as ecologists have only just begun to explore this facet of biological invasions [15].

Implications of mutualistic disruptions for conservation Mutualistic interactions are important for maintaining and generating biodiversity [10] and conservation efforts should aim to ensure the continued functioning of these processes. As well as determining how an alien species enters the pollination or dispersal web, with what kind of species it interacts, how frequently, and the implications of the interactions it establishes, we need to evaluate to what extent it is competitively superior to native species, not only in terms of resource and/or space acquisition, but also in terms of attracting dispersers and pollinators. If an alien is preferred by animal mutualists, its invasiveness and potential impact on the invaded community are amplified [17]. Furthermore, we need to consider that alien species can influence not only the population density and growth, but also the capacity for long-distance dispersal of native species $[29,56]$. The implications of such disruptions for biodiversity conservation are only beginning to be discussed [57].

Given the levels of generalism found in plantpollinator and plant-disperser interactions, it seems appropriate to consider them as networks of interactions involving many species $[13,15]$. Such generalism implies resilience to linked extinctions, but also enables introduced generalists to displace native species, leading to a net loss of diversity. Many of these generalist pollinators and seed dispersers are becoming more abundant as a result of human-aided dispersal and habitat modification $[25,26,39,50]$.

Several relevant hypotheses worth testing emerge from the fact that most interactions in pollination or dispersal networks are asymmetrical, that is, specialist pollinators or dispersers tend to visit plants that accept many pollinator or disperser species, whereas specialist plants are pollinated or dispersed by animals that are themselves generalists [13]: (i) the introduction of an invasive pollinator or disperser that can displace native ones is expected to affect specialist plants more than it does generalist plants, which are more buffered against mutualist losses; (ii) specialist pollinators or dispersers are more prone than are generalist ones to disruptions by 
invasive pollinators or dispersers (which often are competitively superior) as the generalists rely on a wider array of floral or fruit resources; (iii) Invasive alien plants offer more floral or fruit resources than do native plants, and more-rewarding flowers or fruits attract greater numbers of pollinators or seed dispersers, especially the most generalist ones. Thus, in nested communities, specialist plants are more likely to be affected than generalist plants; (iv) plants that depend upon an array of pollinators or dispersers might be less vulnerable to the introduction of an invasive herbivore that decreases plant attractiveness (to at least some of those mutualists) or to the introduction of an invasive predator that causes declines in the populations of such mutualists. Only in the case of a two-way specialist interaction might a herbivore have little impact on the mutualism itself as pollinators or dispersers do not have other alternatives; (v) an invasive herbivore (usually generalist) poses a major risk to specialist pollinators or dispersers as these depend on only a few plant species. Similarly, an invasive predator is also more likely to affect specialist pollinators or dispersers as these might be more easily encountered in the few plant species they pollinate or disperse. Finally, (vi) two-way specialist mutualistic interactions among native plants and pollinators or dispersers will be the least vulnerable to disruption by invasive pollinators or dispersers or by invasive plants because, by definition, specialist pollinators or dispersers are unlikely to share plants whereas specialist plants are unlikely to share pollinators or dispersers.

Landscape restoration programs should explicitly consider mutualistic interactions, paying particular attention to the keystone species in the plant communities that interact with large number of pollinators or dispersers [57]. Special effort should also be invested in maintaining vulnerable 'mutualistic compartments', such as longtongued bees-deep-corolla flowers [58] or large-gaped birds-large fruits [24], rather than protecting species that might have little effect on ecosystem functioning. Special attention should also be paid to highly generalist pollinators, particularly those favoured and introduced by humans (e.g. honeybees). Such pollinators can displace others and have negative effects on plant recruitment, but they can also increase recruitment in other species that have lost their native pollinators [26]. Hence, each particular system will need to be examined to develop an appropriate management strategy.

\section{Conclusions}

The most important causes of plant-animal mutualistic disruptions are shared among different regions of the planet, although their consequences can vary widely. The restoration of 'pristine' pollination and dispersal systems is probably impossible, as changes in land use and species introductions are likely to be irreversible as a result of their natural dynamics as well as the persistence of socioeconomical factors that drive them. As Roubik pointed out [59], the key question is whether such 'new' systems can absorb new species and interactions while simultaneously sustaining complex interactions of native species. Obtaining appropriate knowledge to formulate management plans for the preservation of the functioning of those mutualisms is a challenge for researchers and conservation managers alike.

\section{Acknowledgements}

The work is framed within projects CGL2004-04884-C02-01/BOS and EPIDEMIE EVK2-2000-00736 financed by the Spanish Ministry of Science and the European Union, respectively, to A.T. Support was also provided by the DST-NRF Centre of Excellence for Invasion Biology to D.M.R. We thank Manuel Nogales, Alfredo Valido, Jens Olesen, Tony Whitaker and Don Drake for providing information on their study systems. The article has benefited with comments from Bruce Anderson, Carl Gosper, Steve Johnson, Petr Pyšek and Dan Simberloff. Moreover, Jaboury Ghazoul, Maureen Stanton, and an anonymous reviewer made excellent suggestions to improve it.

\section{References}

1 MacDougall, A.S. and Turkington, R. (2005) Are invasive species the drivers or passengers of change in degraded ecosystems? Ecology 86, 42-55

2 Levine, J.M. et al. (2003) Mechanisms underlying the impacts of exotic plant invasions. Proc. R. Soc. B 270, 775-781

3 Brooks, M.L. et al. (2004) Effects of invasive alien plants on fire regimes. Bioscience 54, 677-688

4 Gurevitch, J. and Padilla, D.K. (2004) Are invasive species a major cause of extinctions? Trends Ecol. Evol. 19, 470-474

5 Kearns, C.A. et al. (1998) Endangered mutualisms: the conservation of plant-pollinator interactions. Annu. Rev. Ecol. Syst. 29, 83-112

6 Paton, D.C. (2000) Disruption of bird-plant pollination systems in Southern Australia. Conserv. Biol. 14, 1232-1234

7 Christian, C.E. (2001) Consequences of biological invasion reveal the importance of mutualism for plant communities. Nature 413, 635-639

8 Traveset, A. and Riera, N. (2005) Disruption of a plant-lizard seed dispersal system and its ecological consequences on a threatened endemic plant in the Balearic Islands. Conserv. Biol. 19, 421-431

9 Bond, W.J. (2004) Do mutualisms matter? Assessing the impact of pollinator and disperser disruption on plant extinction. Phil. Trans. $R$. Soc. $B$ 344, 83-90

10 Herrera, C.M. and Pellmyr, O., eds (2002) Plant-Animal Interactions. An Evolutionary Approach, Blackwell Science

11 Cox, P.A. and Elmqvist, T. (2000) Pollinator extinction in the Pacific islands. Conserv. Biol. 14, 1237-1239

12 Hansen, D.M. et al. (2002) Trees, birds and bees in Mauritius: exploitative competition between introduced honey bees and endemic nectarivorous birds? J. Biogeogr. 29, 721-734

13 Bascompte, J. et al. (2003) The nested assembly of plant-animal mutualistic networks. Proc. Natl. Acad. Sci. U. S. A. 100, 9383-9387

14 Hingston, A.B. et al. (2002) Extent of invasion of Tasmanian native vegetation by the exotic bumblebee Bombus terrestris (Apoidea: Apidae). Austral Ecol. 27, 162-172

15 Olesen, J.M. et al. (2002) Invasion of pollination networks on oceanic islands: importance of invader complexes and endemic super generalists. Div. Distrib. 8, 181-192

16 Memmott, J. and Waser, N. (2002) Integration of alien plants into a native flower-pollination visitation web. Proc. $R$. Soc. B 269, 2395-2399

17 Ghazoul, J. (2002) Flowers at the front line of invasion? Ecol. Entomol. $27,638-640$

18 Ghazoul, J. (2005) Buzziness as usual? Questioning the global pollination crisis. Trends Ecol. Evol. 20, 367-373

19 Celebrezze, T. and Paton, D.C. (2003) Do introduced honeybees (Apis mellifera, Hymenoptera) provide full pollination service to birdadapted Australian plants with small flowers? An experimental study of Brachyloma ericoides (Epacridaceae). Austral Ecol. 28, 129-136

20 Gross, C.L. and Mackay, D. (1998) Honeybees reduce fitness in the pioneer shrub Melastoma affine (Melastomaceae). Biol. Conserv. 86, 169-178

21 Stanton, M.L. (2003) Interacting guilds: moving beyond the pairwise perspective on mutualisms. Am. Nat. 162, S10-S23

22 Butz Huryn, V.M. (1997) Ecological impacts on introduced honey bees. Q. Rev. Biol. 72, 275-297 
23 Gross, C.L. (2001) The effect of introduced honeybees on native bee visitation and fruit-set in Dillwynia juniperina (Fabaceae) in a fragmented ecosystem. Biol. Conserv. 102, 89-95

24 Kelly, D. et al. (2006) Relative (un)importance of introduced animals as pollinators and disperses of native plants. In Biological Invasions in New Zealand (Allen, R.B. and Lee, W.G., eds), Springer (in press)

25 Paini, D.R. (2004) Impact of the introduced honey bee (Apis mellifera) (Hymenoptera: Apidae) on native bees: a review. Austral Ecol. 29, 399-407

26 Goulson, D. (2003) Effects of introduced bees on native ecosystems. Annu. Rev. Ecol. Syst. 34, 1-26

27 Vaughton, G. (1996) Pollination disruption by European honeybees in the Australian bird-pollinated shrub Grevillea barklyana (Proteaceae). Plant Syst. Evol. 200, 89-100

28 Dupont, Y.L. et al. (2004) Impact of introduced honey bees on native pollination interactions of the endemic Echium wildpretii (Boraginaceae) on Tenerife, Canary Islands. Biol. Conserv. 118, 301-311

29 Dick, C.W. et al. (2003) Pollen dispersal of tropical trees (Dinizia excelsa: Fabaceae) by native insects and African honeybees in pristine and fragmented Amazonian rainforest. Mol. Ecol. 12, 753-764

30 Kato, M. and Kawakita, A. (2004) Plant-pollinator interactions in New Caledonia influenced by introduced honey bees. Am. J. Bot. 91, 1814-1827

31 Olesen, J.M. et al. (1998) Mauritian red nectar remains a mystery. Nature 393,529

32 Spurr, E.B. and Anderson, S.H. (2004) Bird species diversity and abundance before and after eradication of possums and wallabies on Rangitoto Island, Hauraki Gulf. N. Z. J. Ecol. 28, 143-149

33 Vázquez, D.P. and Simberloff, D. (2004) Indirect effects of an introduced ungulate on pollination and plant reproduction. Ecol. Monogr. 74, 281-308

34 Gómez, J.M. (2003) Herbivory reduces the strength of pollinatormediated selection in the Mediterranean herb Erysimum mediohispanicum: consequences for plant specialization. Am. Nat. 162, $242-256$

35 Nogales, M. and Medina, F.M. (1996) A review of the diet of feral domestic cats (Felis silvestris f. catus) on the Canary Islands, with new data from the laurel forest of La Gomera. Z. Saugertierkunde 61, 1-6

36 Traveset, A. and Sáez, E. (1997) Pollination of Euphorbia dendroides by lizards and insects: spatio-temporal variation in patterns of flower visitation. Oecologia 111, 241-248

37 Jourdan, H. et al. (2001) Little fire ant invasion (Wasmannia auropunctata) as a threat to New Caledonian lizards: evidences from a sclerophyll forest (Hymenoptera: Formicidae). Sociobiology 38, 283-301

38 Holway, D.L. et al. (2002) The cause and consequences of ant invasions. Annu. Rev. Ecol. Syst. 33, 181-233

39 Richardson, D.M. et al. (2000) Plant invasions - the role of mutualisms. Biol. Rev. Camb. Philos. Soc. 75, 65-93

40 Moragues, E. and Traveset, A. (2005) Effect of Carpobrotus spp. on the pollination success of native plant species of the Balearic Islands. Biol. Conserv. 122, 611-619

41 Brown, B.J. et al. (2002) Competition for pollination between an invasive species (purple loosestrife) and a native congener. Ecology 83, 2328-2336

42 Graves, S.D. and Shapiro, A.M. (2003) Exotics as host plants of the California butterfly fauna. Biol. Conserv. 110, 413-433

43 Ferguson, R.N. and Drake, D.R. (1999) Influence of vegetation structure on spatial patterns of seed deposition by birds. $N$. Z . J. Bot. 37, 671-677

44 Dungan, R.J. et al. (2002) Contribution of possums to seed rain and subsequent seed germination in successional vegetation, Canterbury, New Zealand. N. Z. J. Ecol. 26, 121-128

45 Riera, N. et al. (2002) Breakage of mutualisms by exotic species: the case of Cneorum tricoccon L. in the Balearic Islands (Western Mediterranean Sea). J. Biogeogr. 29, 713-719

46 Gournell, J. et al. (2004) Alien species and interspecific competition: effects of introduced eastern grey squirrels on red squirrel population dynamics. J. Anim. Ecol. 73, 26-35

47 Sallabanks, R. (1993) Fruiting plant attractiveness to avian seed dispersers: native vs. invasive Crataegus in Western Oregon. Madrono 40, 108-116
48 Oatley, T.B. (1984) Exploitation of a new niche by the Rameron Pigeon Columba arquatrix in Natal. In Proceedings of the Fifth Pan-African Ornithological Congress (Ledger, J.A., ed.), pp. 323-330, Southern African Ornithological Society

49 Williams, P.A. and Karl, B.J. (2002) Birds and small mammals in kanuka (Kunzea ericoides) and gorse (Ulex europaeus) scrub and the resulting seed rain and seedling dynamics. N. Z. J. Ecol. 26, 31-41

50 Simberloff, D. and Von Holle, B. (1999) Positive interactions of nonindigenous species: invasional meltdown? Biol. Inv. 1, 21-32

51 Morales, C.L. and Aizen, M.A. (2002) Does invasion of exotic plants promote invasion of exotic flower visitors? A case study from the temperate forests of the southern Andes. Biol. Inv 4, 87-100

52 Kato, M. et al. (1999) Impact of introduced honeybees, Apis mellifera, upon native bee communities in the Bonin (Ogasawara) Islands. Res. Popul. Ecol. (Kyoto) 41, 217-228

53 Stout, J.C. et al. (2002) Pollination of the invasive exotic shrub Lupinus arboreus (Fabaceae) by introduced bees in Tasmania. Biol. Conserv. 106, 425-434

54 D'Antonio, C.M. (1990) Seed production and dispersal in the nonnative, invasive succulent Carpobrotus edulis (Aizoaceae) in coastal strand communities of Central California. J. Appl. Ecol. 27, 693-702

55 Bourgeouis, K. et al. (2005) Invasional meltdown potential: facilitation between introduced plants and mammals on French Mediterranean islands. Ecoscience 12, 248-256

56 Trakhtenbrot, A. et al. (2005) The importance of long-distance dispersal in biodiversity conservation. Div. Distrib. 11, 173-181

57 Handel, S.N. (1997) The role of plant-animal mutualisms in the design and restoration of natural communities. In Restoration Ecology and Sustainable Development (Urbanska, K.M. et al., eds), pp. 111-132, Cambridge University Press

58 Corbet, S.A. (2000) Conserving compartments in pollination webs. Conserv. Biol. 14, 1229-1231

59 Roubik, D.W. (2000) Pollination system stability in Tropical America. Conserv. Biol. 14, 1235-1236

60 Thorp, R.W. et al. (2000) Pollen and nectar resource overlap among bees on Santa Cruz Island. In Proceedings of the Fifth California Islands Symposium (Browne et al., eds), pp. 261-267, MBC Applied Environmental Sciences

61 England, P.R. et al. (2001) A molecular genetic assessment of matingsystem variation in a naturally bird-pollinated shrub: contributions from birds and introduced honeybees. Conserv. Biol. 15, 1645-1655

62 Aizen, M.A. and Feinsinger, P. (1994) Habitat fragmentation, native insect pollinators, and feral honey bees in Argentine "Chaco Serrano". Ecol. Appl. 4, 378-392

63 Hingston, A.B. (2005) Does the introduced bumblebee, Bombus terrestris (Apidae), prefer flowers of introduced or native plants in Australia? Aust. J. Zool. 53, 29-34

64 Dafni, A. and Shmida, A. (1996) The possible ecological implications of the invasion of Bombus terrestris (L.) (Apidae) at Mt Carmel, Israel. In The Conservation of Bees (Matheson, A. et al., eds), pp. 183-200, The Linnean Society of London Symposium Series n ${ }^{\circ} 18$, Academic Press

65 Blancafort, X. and Gómez, C. (2005) Consequences of the Argentine ant, Linepithema humile (Mayr) invasion on pollination of Euphorbia characias (L.) (Euphorbiaceae). Acta Oecol. 28, 49-55

66 Fritts, T.H. and Rodda, G.H. (1998) The role of introduced species in the degradation of island ecosystems: a case history of Guam. Annu. Rev. Ecol. Syst. 29, 113-140

67 Waring, G.H. et al. (1993) Study on the use of alien versus native plants by nectarivorous forest birds on Maui, Hawaii. Auk 110, 917-920

68 Chittka, L. and Schürkens, S. (2001) Successful invasion of a floral market. Nature 411, 653

69 Ghazoul, J. (2004) Alien abduction: disruption of native plantpollinator interactions by invasive species. Biotropica 36, 156-164

70 Gómez, C. et al. (2003) Effects of the Argentina ant Linepithema humile on seed dispersal and seedling emergence of Rhamnus alaternus. Ecography 26, 532-538

71 Carney, S.E. et al. (2003) Invasive Argentine ants (Linepithema humile) do not replace native ants as seed dispersers of Dendromecon rigida (Papaveraceae) in California, USA. Oecologia 135, 576-582

72 Kawakami, K. and Higuhi, H. (2003) Interspecific interactions between the native and introduced white-eyes in the Bonin Islands. Ibis $145,583-592$ 